\title{
The Evaluation of Diabetes Mellitus as an Independent Risk Factor for Gastroesphageal Variceal Bleeding in Cirrhotic Patients
}

\author{
DINA A. LABIB, M.Sc.*; HEGAZY M. HEGAZY, M.D.*; DESOUKY E. ABOAMMO, M.D.** and \\ GHADA M. ELGHAZALY, M.D. \\ The Departments of Internal Medicine* and Clinical Pathology**, Faculty of Medicine, Tanta University
}

\begin{abstract}
Background: Diabetes mellitus has been reported to increase the risk of complications of liver cirrhosis and subsequent survival. Varices constitute the most common lethal cause of mortality in cirrhotic patients, consequently the association between DM and gastro-esophageal variceal bleeding becomes the focus of attention.
\end{abstract}

Aim of Study: Is to elucidate whether DM is an independent risk factor for gastro-esophageal variceal bleeding in cirrhotic patients.

Patients and Methods: This cross-sectional study was conducted in Internal Medicine Department, Faculty of Medicine, Tanta University Emergency Hospital at Gastroendoscopy Unit from September 2017 to July 2018 and included 120 patients. Group (A): Diabetic cirrhotic patients with upper gastrointestinal variceal bleeding. Group (B): Nondiabetic cirrhotic patients with upper gastrointestinal variceal bleeding. The patients were subjected to history taking, laboratory investigations including: $\mathrm{CBC}, \mathrm{AST}, \mathrm{ALT}$, bilirubin, albumin, blood urea, serum creatinine, $\mathrm{Pa}$, INR, HBVs Ag, anti $\mathrm{HCV} \mathrm{Ab}, \mathrm{RBG}, \mathrm{HbA} 1 \mathrm{c}$ and gastrointestinal endoscope.

Results: Of the 120 patients, there were 67 (55.8\%) diabetics, $53(44.2 \%)$ were non-diabetics, they were $47(39.2 \%)$ child A, 73 (60.8\%) child B \& C. GEVB incidence was higher in child $\mathrm{B} \& \mathrm{C}$ than child $\mathrm{A}$, also as regard sub grouping in child $\mathrm{A}$, the diabetic patients were $32(68.1 \%)$ while nondiabetics were $15(31.9 \%)$ and in child B \& C diabetics were $35(47.9 \%)$ and non-diabetics were $38(52.1 \%)$ with $p$-value (0.030), there was significant higher ratio of ascites, encephalopathy and recurrence of attacks of GEVB in child B \& C than child $\mathrm{A}$, there was significant higher ratio of ascites, previous attacks of encephalopathy and recurrence of attacks of GEVB in diabetics than non-diabetics and there was statistically significant higher incidence of recurrence of attacks of GEVB with HBAlc $>7$.

Conclusion: The incidence of GEVB was significantly associated with DM in cirrhotic patients, especially in patients with Child-Pugh Class A.

Key Words: Liver cirrhosis - Diabetes mellitus - Gastroesphageal variceal bleeding.

Correspondence to: Dr. Dina A. Labib, The Department of Internal Medicine, Faculty of Medicine, Tanta University

\section{Introduction}

LIVER cirrhosis is considered to be the final destination of virtually all chronic liver diseases, the rate of mortality in decompensated patients is about $20-57 \%$ in one year, liver cirrhosis leads to many life-threatening complications, of these complications (Ascites, Spontaneous Bacterial Peritonitis (SBP), hepatic encephalopathy, and gastroesophageal variceal bleeding) [1,2]

Gastroesophageal Variceal Bleeding (GEVB) is undoubtedly the most critical event with the highest risk of mortality [3], that is directly related to portal hypertension, the mortality rate in cirrhotic patients with upper GIT bleeding ranges from 3.5 to $7.4 \%[4]$

There are two types of diabetes mellitus concomitant with chronic liver diseases, conventional type $2 \mathrm{DM}$ that is either develops in advance or simply coincides with chronic liver disease and also there is hepatogenous DM, in which chronic liver disease evently leads to chronic disturbances in glucose metabolism, thus it is called hepatogenous diabetes $[\mathbf{5 , 6}]$.

Recent research has revealed that $60-90 \%$ of patients with liver cirrhosis have glucose intolerance, including HD [7,8], so the presence of hepatogenous diabetes may consider as an indicator for advanced disease of the liver [9].

There is rising evidence that both hepatogenous diabetes and type 2 diabetes mellitus (DM) are associated with an increased potential of cirrhotic complications regardless of the-etiology and subsequently the increased rate of mortality [10-12]

Recently, insulin resistance that is a characteristic of type $2 \mathrm{DM}$, has been considered to be a 
predictor of portal hypertension [13] and subsequently development of esophageal varices [14]

However, according to our knowledge, the association between DM and gastro-esophageal variceal bleeding is still confounded, so the aim of our study is to elucidate that whether DM is an independent risk factor for GEVB in cirrhotic patients.

\section{Patients and Methods}

This cross-sectional observational study was conducted in Internal Medicine Department at Gastro-Endoscopy Unit, Faculty of Medicine, Tanta University, and has been completed from September 2017 to July 2018 , and included 120 randomly selected cirrhotic patients admitted to Tanta University Emergency Hospital at Gastro-Endoscopy Unit with gastro-espohageal variceal bleeding with and without diabetes mellitus.

\section{Inclusion criteria:}

1- >18 years.

2- Patients of both sexes.

3- Patients who can give informed consent by themselves.

4- Cirrhotic patients with variceal bleeding with and without DM.

\section{Exclusion criteria:}

1 - Age $<18$ years.

2- Other causes of bleeding rather than varices in gastro-esophageal endoscope.

3- Other co-morbidities as cardiac and renal diseases.

4- Patients with HCC.

5- Patients who refused to participate in this study.

All cases included in the study were subjected to the following after obtaining an informed consent:

- Full history taking.

- Complete clinical examination.

- Laboratory investigations including: Complete Blood Count (CBC), liver function tests (AST, ALT, bilirubin and albumin), renal function tests (blood urea, serum creatinine), prothrombin time and activity, virology (HBV surface antigen, HCV antibodies), random blood sugar, hemoglobin A1c.

- Gastrointestinal endoscope.
1- Diagnosis of DM is based on the [American Diabetes Association criteria] [15], which include the following:

1- Fasting plasma glucose level > $(126 \mathrm{mg} / \mathrm{dL})$, symptoms of hyperglycemia.

2- Random plasma glucose $>(200 \mathrm{mg} / \mathrm{dL})$.

3- Glycated hemoglobin (HbA1C) $>6.5 \%$.

2- Diagnosis of cirrhosis is based on:

1- Ultrasound findings suggestive of cirrhosis, along with clinical data, such as (thrombocytopenia or other signs of portal hypertension), and laboratory tests.

2- The severity of liver cirrhosis was assessed using the child-Pugh score.

The patients were divided to two groups:

Group $(A)$ : Patients with gastro-esophageal variceal bleeding with diabetes mellitus, they were 67 patients.

Group (B): Patients with gastro-esophageal variceal bleeding without diabetes mellitus, they were 53 patients.

- All patients were followed for 48 hours for detection of early complications, early re bleeding, and mortality.

- This study was approved by Tanta Research Ethics Committee as a part of the Quality Assurance Unit in the Faculty of Medicine. All patients gave written informed consents.

\section{Statistical analysis:}

Statistical presentation and analysis of the present study used SPSS Version 19. For numerical values the range mean and standard deviations were calculated. The differences between two mean values were used using student's $t$-test. For numerical data with small sample size in subcategories, the normal distribution was not guaranteed so Mann-Whitney test was used to compare difference in mean values instead of $t$-test. For categorical variable the number and percentage were calculated and differences between subcategories were tested by Fisher and Monte Carlo exact test as appropriate. The level of significant was adopted at $p<0.05$.

\section{Results}

Baseline features of the 120 patients are shown in (Table 1), this present study found that out of 120 cirrhotic patients with GEVB there were 67 $(55.8 \%)$ diabetics, $53(44.2 \%)$ were non-diabetics, they were 47 (39.2\%) Child A, 73 (60.8\%) Child $\mathrm{B} \& \mathrm{C}$. 
Table (1): Clinicopathological data of patients.

\begin{tabular}{ll}
\hline Characteristics & $(\mathrm{n}=120)$ \\
\hline Age: & \\
Mean \pm S.D & $58.60 \pm 9.45$ \\
Gender: & \\
Male & $96(80 \%)$ \\
Female & $24(20 \%)$ \\
BMI: & \\
Mean \pm S.D & $28.49 \pm 3.33$ \\
Child-Pugh score: & \\
Child A & $47(39.2 \%)$ \\
Child B & $59(49.2 \%)$ \\
Child C & $14(11.7 \%)$ \\
Diabetes mellitus: & \\
Diabetic group (Group A) & $67(55.8 \%)$ \\
Non-iabetic group (Group B) & $53(44.2 \%)$ \\
Anti-HCV Ab \& HBs antigen: & \\
Anti-HCV Ab (+) & $99(82.5 \%)$ \\
Anti-HCV Ab \& HBs antigen positive & $3(2.5 \%)$ \\
Anti-HCV Ab \& HBs antigen negative & $18(15 \%)$ \\
Encephalopathy: & \\
No & $89(74.2 \%)$ \\
Yes & $31(25.8 \%)$ \\
Ascites: & \\
No & \\
Yes & \\
Attacks of GEVB: & \\
First time & \\
Recurrent & \\
\hline & \\
\hline &
\end{tabular}

The present study found that patients with Child B \& C had statistically significant lower random blood glucose than child A Fig. (1), by comparing between patients with child $A$ and patients with Child B \& C as regard recurrence of attacks of GEVB, there was statistically significant higher ratio of recurrence of GEVB among patients with Child B \& C than patients with Child A (Table 2). Diabetes mellitus was significantly associated with patients of Child B \& C 35 (52.2\%) more than child A $32(47.8 \%)$ with $(p$-value $=0.030)($ Table $3)$.

Comparison between different clinical and laboratory parameters of patients with Child A: Patients with diabetes had statistically significantly higher platelet number, higher blood urea \& serum creatinine, higher incidence of encephalopathy, higher ratio of recurrence of bleeding attacks of GEVB than non-diabetics Figs. (2-6), comparison between different clinical and laboratory parameters of patients with Child B \& C, the diabetic patients were statistically significant higher in blood urea\& serum creatinine level, higher ratio of ascites, previous attacks of encephalopathy and recurrence of attacks of GEVB Figs. (7-11).
DM significantly correlated with GEVB in diabetic patients with Child A (Table 4).

There was no significant effect of either HD or type $2 \mathrm{DM}$ on GEVB in both child A and Child B $\& \mathrm{C}$ as in (Table 5), by comparing between diabetic patients with recurrent attacks of GEVB and diabetic patients presented with first attack of GEVB as regard HBA1c (Table 6), there was statistically significant higher ratio of recurrence of attacks of GEVB in diabetic patients with poor glycemic control HBA1c ( $>7)$ than patients with HBA1c $(<7)$. On follow-up of $t$ he patients for 48 hours in this study only ten patients experienced complications, seven patients had recurrent attacks of GEVB in about three weeks from the last attack of GEVB, six of them were diabetics in which 2 patients were child A, 4 patients were Child B \& C, and one of them was non-diabetic (Child B). Three patients had hepatic encephalopathy after endoscope all of them were diabetics (Child B \& C).

Table (2): GEVB among patients with Child B \& C than patients with Child A.

\begin{tabular}{llll}
\hline Attacks of GEVB & \multicolumn{1}{c}{ A } & B \& C & Total \\
\hline First: & & & \\
$\mathrm{N}$ & 19 & 15 & 34 \\
$\%$ & $40.4 \%$ & $20.5 \%$ & $28.3 \%$ \\
Recurrent: & & & \\
$\mathrm{N}$ & 28 & 58 & 86 \\
$\%$ & $59.6 \%$ & $79.5 \%$ & $71.7 \%$ \\
Total: & & & \\
$\mathrm{N}$ & & & \\
$\%$ & 47 & 73 & 120 \\
Chi-square: & $100.0 \%$ & $100.0 \%$ & $100.0 \%$ \\
$\chi^{2}$ & & & \\
$p$-value & & 5.564 & \\
\hline
\end{tabular}

Table (3): Diabetes mellitus was significantly associated with patients of Child B \& C more than child A.

\begin{tabular}{ccccc}
\hline & Child A & Child B \& C & $\chi^{2}$ & $p$-value \\
\hline DM & $32(47.8 \%)$ & $35(52.2 \%)$ & 4.703 & $0.030^{*}$ \\
\hline
\end{tabular}

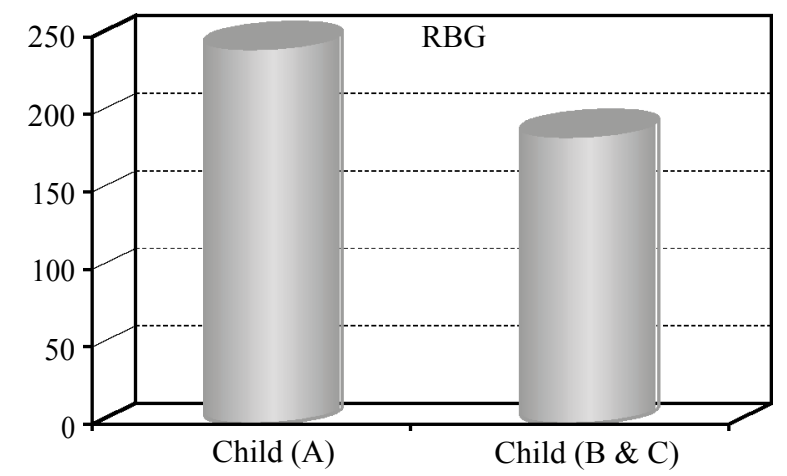

Fig. (1): Comparing between patients with child $\mathrm{A}$ and patients with Child B \& C. 


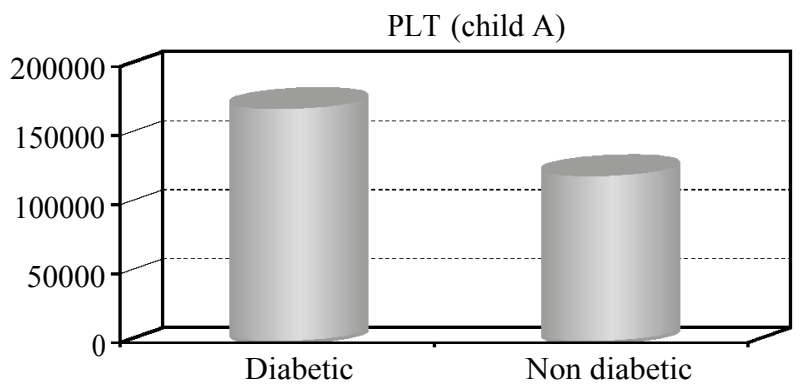

Fig. (2):

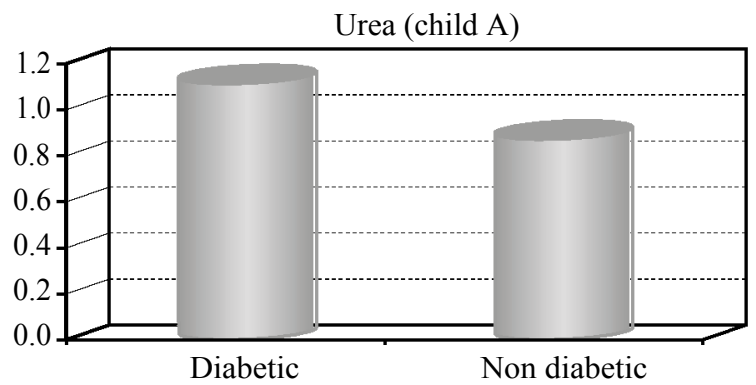

Fig. (3):

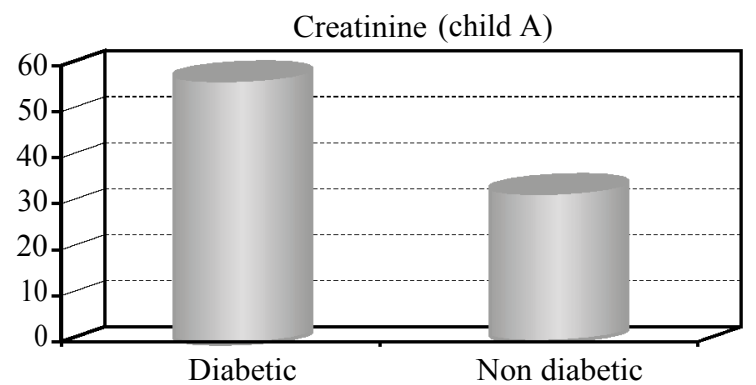

Fig. (4):

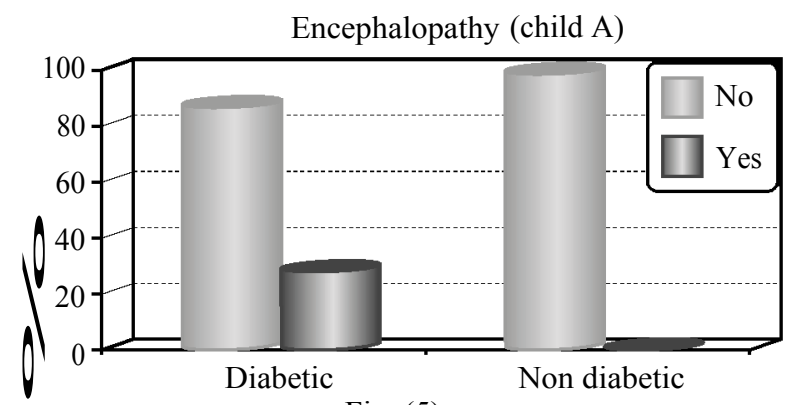

Fig. (5):

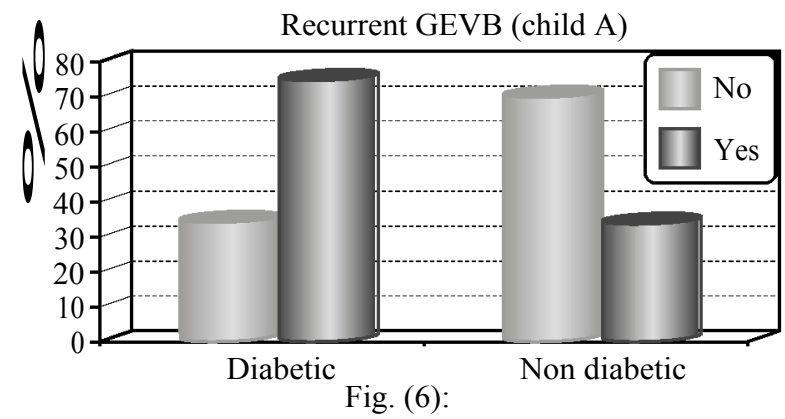

Fig. (2-6): Comparison between different clinical and laboratory parameters of patients with Child B \& C.

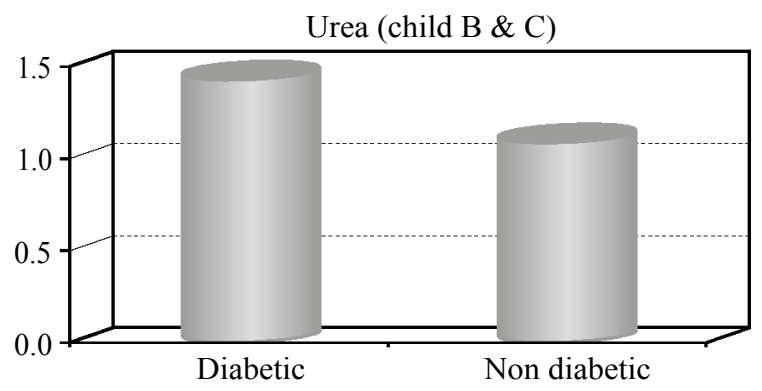

Fig. (7):

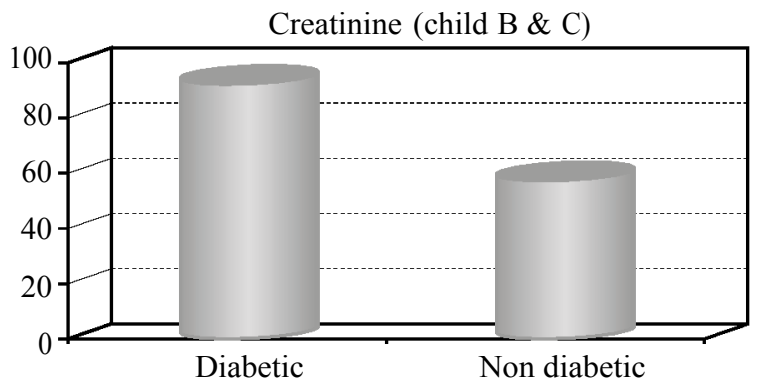

Fig. (8):

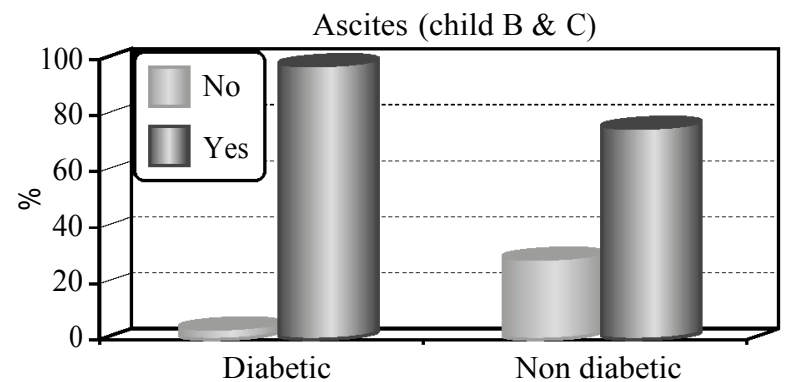

Fig. (9):

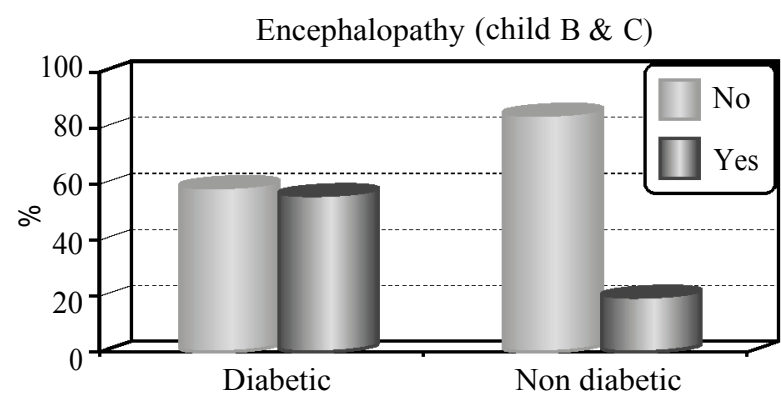

Fig. (10):

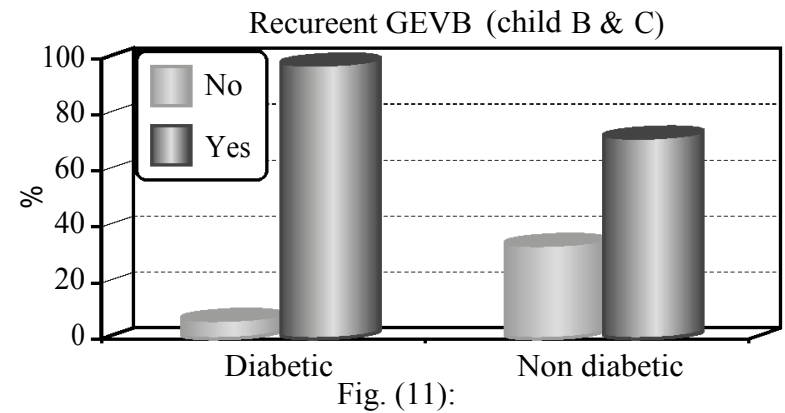

Fig. (7-11): Higher ratio of ascites, previous attacks of encephalopathy and recurrence of attacks of GEVB. 
Table (4): DM significantly correlated with GEVB in diabetic patients with Child A.

\begin{tabular}{ccccc}
\hline & DM & Non DM & $x^{2}$ & $p$-value \\
\hline Child A & $32(68.1 \%)$ & $15(31.9 \%)$ & 4.703 & $0.030^{*}$ \\
\hline
\end{tabular}

Table (5): There was no significant effect of either HD or type 2 DM on GEVB in both child A and Child B $\& \mathrm{C}$.

\begin{tabular}{llll}
\hline Type of DM & \multicolumn{1}{c}{$\mathrm{A}$} & $\mathrm{B} \& \mathrm{C}$ & Total \\
\hline$H D:$ & & & \\
$\mathrm{N}$ & 12 & 13 & 25 \\
$\%$ & $37.2 \%$ & $37.1 \%$ & $37.3 \%$ \\
$T 2 D M:$ & & & \\
$\mathrm{N}$ & & 22 & 42 \\
$\%$ & 20 & $62.9 \%$ & $62.7 \%$ \\
Total: & $62.8 \%$ & & \\
$\mathrm{~N}$ & & 35 & 67 \\
$\%$ & 32 & $100.0 \%$ & $100.0 \%$ \\
Chi-square: & $100.0 \%$ & & \\
$\chi^{2}$ & & 0.012 & \\
$p$-value & & 0.976 & \\
\hline
\end{tabular}

Table (6): Comparing between diabetic patients with recurrent attacks of GEVB and diabetic patients presented with first attack of GEVB as regard HBA1c.

\begin{tabular}{clll}
\hline HBA1c & First & Recurrent & Total \\
\hline$<7:$ & & & \\
$\mathrm{N}$ & 4 & 3 & 7 \\
$\%$ & $33.3 \%$ & $5.5 \%$ & $10.4 \%$ \\
$>7:$ & & & \\
$\mathrm{N}$ & 8 & 52 & 60 \\
$\%$ & $66.7 \%$ & $94.5 \%$ & $89.6 \%$ \\
Total: & & & \\
$\mathrm{N}$ & 12 & 55 & 67 \\
$\%$ & $100.0 \%$ & $100.0 \%$ & $100.0 \%$ \\
Chi-square: & & & \\
$\chi^{2}$ & & 8.183 & \\
$p$-value & & $0.004 *$ & \\
\hline
\end{tabular}

\section{Discussion}

Liver cirrhosis has been strongly associated with DM and vice-viscera. Cirrhosis may contribute to the development of DM through numerous factors [16], DM also is associated with greater incidence of complications and mortality in cirrhosis [17]. As insulin can contribute to PHT. Hyperglycemia also induces splanchnic hyperemia and increases portal pressure and bacterial translocation, which also result in an increase in variceal hemorrhage risk [18].
In addition, the vasculopathy which impairs mucosal integrity and impairs mucosal healing, leading to more severe bleeding and makes the control of bleeding from the lesions more difficult $[19,20]$.

There was significant higher level of platelets between diabetics and non-diabetics in Child A, this is in agreement with, Jáquez Quintana et al., [21], Elbaih et al., [22], and this is in contrary to Ramachandran et al., [23] who showed lower level of platelets in diabetic group of cirrhotic patients.

There was increased level of blood urea, serum creatinine in diabetics than non-diabetics, similarly to Harrison et al., [24], and Gines et al., [25] they found that diabetes was associated with specific changes in the hepatic micro-circulation, called 'hepatic micro-angiopathy', and thus tempting to speculate that diabetes was associated with microcirculatory changes in the liver and the kidneys, Elbaih et al., [22] who showed that the serum urea, was higher in diabetic group with GEVB than nondiabetic group.

This is in contrary to Chen et al., [26] who reported the presence of diabetes was dissociated with renal function by means of serum creatinine or estimated glomerular filtration rate.

There was higher incidence of ascites in diabetic patients than non-diabetics, this is in agreement with Elkrief et al., [27] reported that diabetes was associated with the development of ascites, in hepatitis C-related cirrhosis, also Liu et al., [28] reported that diabetes was associated with clinical decompensation events in patients with cirrhosis, in contrary, Elbaih AH et al., [22], also Gundling et al., [29] who reported that ascites and $\mathrm{PH}$ occurred more frequently in non-diabetic cirrhotic patients than in the diabetic subgroup, this difference could be explained by the relative higher number of patients with Child B \& $\mathrm{C}$ in non-diabetics than diabetics in the previous study but in the present study there is significant correlation of DM with Child B \& C than Child A.

In this study there was statistically significant higher incidence of encephalopathy in diabetic patients than non-diabetics this is explained by increased susceptibility of infection and complications in DM. Similar findings by Butt et al., [30] showed that DM was associated with the presence and severity of hepatic encephalopathy, and Zeeshan et al., [31] who found that diabetes was associated with $\mathrm{HE}$ even after adjusting for age and gender. 
Patients in this study were classified into Child A, they were 47 (39.2\%) while Child B \& C were $73(60.8 \%)$ and hence Child B \& C was associated with GEVB this is in agreement with Thapa et al., [32] who reported that cirrhotic patients with higher Child Pugh's score had higher grades of esophageal varices leading to presentation with hematemesis, Deepak et al., [33] found that varices increases with advanced child score, and Ashraf et al., [34] reported that Child-Pugh score was significant with advanced scores and in prediction of esophageal varices.

Also in the present study we found that diabetes mellitus was significantly associated with patients of Child B \& C 35 (52.2\%) more than Child A 32 $(47.8 \%)$ with $(p$-value $=0.030)$ this is supported by several studies which have shown that DM is associated with more severe liver disease and its presence is associated with an increase in the risk of cirrhosis complications, this is in agreement with, García-compeán et al., [35], Perme et al., [36] who found that most common findings among diabetic patient were ascites (95\%), anemia, upper gastrointestinal bleeding, complications of CLD were slightly higher among diabetic patient, similarly Jeon et al., [37] reported that, the presence of HD showed significant correlation with high ChildPugh's score, variceal hemorrhage.

In contrary to Chen et al., [26] who reported that the prevalence of diabetes was dissociated with Child-Pugh, also Arshad et al., [38] stated that chronic hepatitis $\mathrm{C}$, ascites, esophageal varices, modified Child-pugh class and MELD score were not different in diabetics as compared to nondiabetics, this different results from our study may need larger number of the sample taken and more researches about this relation.

In this study the incidence of GEVB was significantly higher in cirrhotic patients with DM than in cirrhotic patients without DM, this is in agreement with, Huang et al., [39] said that $\mathrm{CHC}$ patients who develop diabetes are at an increased risk of liver cirrhosis and its decompensation over time, Perme et al., [36] found that most common finding among diabetic patient was ascites, anemia, upper gastrointestinal bleeding.

In contrary to Jáquez Quintana et al., [21], also Kwon., [40] found that there was no significant difference of GEVB between diabetic group and non-diabetic one in compensated liver disease. This is because these patients in the previous study were evaluated according to cause of death which included many complications of DM which accom- pany cirrhosis not only GEVB and its relation to child score and also in this the present study no long term follow-up was done as the previous study.

This study revealed that, DM significantly correlated with GEVB in patients with Child-Pugh Class A, with 32(68.1\%) diabetic patients and 15 $(31.9 \%)$ non-diabetics with $(p$-value $=0.030)$, so DM was associated with GEVB in cirrhotic patients, especially in those with Child-Pugh Class A. This is in agreement with Yang et al., [41], Khafaga et al., [42] who reported that the diabetic group (all most of them compensated) showed statistically significant unstable course; more attacks of melena, Saeed et al., [43] reported that diabetes mellitus was associated with higher risk of developing decompensated cirrhosis in chronic hepatitis $\mathrm{C}$ patients with significant correlation with GEVB.

There was no significant effect of either HD or type 2 DM on GEVB in both Child A and Child B $\& \mathrm{C}$, this is in agreement with Orsi, et al., [44] who reported that HD not differ from type $2 \mathrm{DM}$ as regard Child score, and their study did not reveal any difference in complications or prognosis of liver disease between them. Yang et al., [41] mentioned that either hepatogenous diabetes or type 2 diabetes mellitus was associated with an increased risk of cirrhotic complications for example GEVB. Also Kumar et al., [45], reported that there was generally no difference between both hepatogenous diabetes or type 2 diabetes mellitus as regard cirrhotic complications.

As regard the recurrence of attacks of GEVB between Child B \& C and Child A: In this study there was significant higher recurrence in patients with Child B and C than Child A, similar to $\mathrm{Hu}$ naysh, [46] who showed that CTP as significant predictor of early re-bleeding, and Groza et al., [47] who reported that the CTP, a high INR were the predictors for re-bleeding after variceal hemorrhage. This is in contrary to Sarwar et al., [48] who showed that CTP didn't shown predictability for re-bleeding from esophageal varices, Ebrahimi et al., [49], who showed that CTP score was not effective as a predictive factor of re-bleeding this difference in both studies may need more researches and also can be explained by limited capacity of Child-Pugh score to discriminate disease severity and involvement of other factors that are effective in predicting re-bleeding as low albumin, higher bilirubin, higher INR level, higher blood urea and serum creatinine, higher ratio of ascites in $B$ \& $C$ than $\mathrm{A}$, on the other hand, socio-economic differences of patients and their attend towards the 
treatment of the disease were probably other effective factors in re-bleeding [50,51].

In this study, the recurrence of attacks of GEVB was higher in diabetic patients than non-diabetics, this is in agreement with Moreau et al., [52] who stated that diabetes mellitus co-existing with cirrhosis was be one of the factors involved in the genesis of variceal bleeding as well as re-bleeding, Khafaga et al., [42] and Assem et al., [51], also reported that diabetes mellitus was associated with higher re bleeding rates.

In the present study the poor glycemic control with $\mathrm{HbA} 1 \mathrm{c}>7$ was associated with increased risk of GEVB, this is supported by Tijera et al., [53] who found that $\mathrm{HbA} 1 \mathrm{c}>8.0 \%$ was associated with all causes of mortality when diabetes coexists with cirrhosis, Gundling et al., [29] showed that diabetics with acute gastrointestinal bleeding had higher mean $\mathrm{HbA} 1 \mathrm{c}$ values than those without bleeding, also Hsiang et al., [54] reported that the presence of DM and poor diabetic control (glycosylated hemoglobin $>7.0 \%$ ) significantly increased the rate of cirrhosis complications and reduced survival in patients with HBV cirrhosis.

In contrary to, Holstein et al., [11] who showed that those patients with diabetes and gastrointestinal bleeding had markedly lower HbA1c values than those without bleeding, Assem et al., [51] reported that there was no significant difference regarding mean $\mathrm{HbA} 1 \mathrm{c}$ about variceal re-bleeding. Possible explanation is that the patients in the present study had poor glycemic control and repeated attacks of GEVB in which there was high levels of blood sugar and higher HBA1c [55].

\section{Conclusion:}

We concluded that GEVB generally was higher in Child B \& C than Child A, and DM was associated more with complications of cirrhosis and consequently with Child B \& C. The incidence of GEVB was significantly higher in cirrhotic patients with DM than in cirrhotic patients without DM, also DM had a significant effect on GEVB especially in patients with Child-Pugh Class A. It is worth-mentioning that the type of DM whether (HD) or (type $2 \mathrm{DM}$ ) had no significant effect on GEVB in both Child A and Child B \& C, also the risk of recurrence of attacks of GEVB increases in patients with poor glycemic control HbAlc $>7$.

\section{References}

1- D'AMICO G., GARCIA-TSAO G. and PAGLIARO L.: Natural history and prognostic indicators of survival in cirrhosis: A systematic review of 118 studies. J. Hepatol., 44 (1): 217-31, 2006.
2- De FRANCHIS R.: Evolving consensus in portal hypertension. Report of the Baveno IV consensus workshop on methodology of diagnosis and therapy in portal hypertension. J. Hepatol., 43 (1): 167-76, 2005.

3- GARCIA-TSAO G. and LIM J.K.: Members of Veterans Affairs Hepatitis C Resource Center Program. Management and treatment of patients with cirrhosis and portal hypertension: Recommendations from the Department of Veterans Affairs Hepatitis C Resource Center Program and the National Hepatitis C Program. Am. J. Gastroenterol., 104 (7): 1802-29, 2009.

4- LEONTIADIS G.I., MOLLOY BLAND M., MOAYYEDI P., et al.: Effect of comorbidity on mortality in patients with peptic ulcer bleeding: Systematic review and meta analysis, Am. Gastroenterol., 108 (3): 331-45, 2013.

5- GARCÍA-COMPEÁN D., JÁQUEZ-QUINTANA J.O., LAVALLE-GONZÁLEZ F.J., et al.: The prevalence and clinical characteristics of glucose metabolism disorders in patients with liver cirrhosis. A prospective study. Ann. Hepatol., 11 (2): 240-48, 2012.

6- PICARDI A., D'AVOLA D., GENTILUCCI U.V., et al. Diabetes in chronic liver disease: From old concepts to new evidence. Diabetes Metab. Res. Rev., 22 (4): 27483, 2006.

7- PAZHANIVEL M. and JAYANTHI V.: Diabetes mellitus and cirrhosis liver. Minerva Gastroenterol. Dietol., 56 (1): 7-11, 2010.

8- NISHIDA T., TSUJI S., TSUJII M., et al.: Oral glucose tolerance test Predicts prognosis of patients with liver cirrhosis. Am. J. Gastroenter., 101 (1): 70-5, 2007.

9- DEL VECCHIO BLANCO C., GENTILE S., MARMO R., et al.: Alterations of glucose metabolism in chronic liver disease. Diabetes Res. Clin. Pract., 8 (1): 29-36, 1990.

10- TROMBETTA M., SPIAZZI G., ZOPPINI G., et al.: Type 2 diabetes and chronic liver disease in the Verona diabetes study. Aliment. Pharmacol. Ther., 22 (2): 24-7, 2005.

11-HOLSTEIN A., HINZE S., THIESSEN E., et al.: Clinical implications of hepatogenous diabetes in liver cirrhosis. J. Gastroenterol. Hepatol., 17 (6): 677-81, 2002.

12- De MARCO R., LOCATELLI F., ZOPPINI G., et al.: Cause-specific mortality in type 2 diabetes. The Verona Diabetes Study. Diabetes Care, 22 (5): 756-61, 1999.

13- FRANCQUE S., VERRIJKEN A., MERTENS I., et al.: Visceral adiposity and insulin resistance are independent predictors of the presence of non-cirrhotic NAFLD-related portal hypertension. Int. J. Obes. (Lond), 35 (2): 270-8, 2011.

14- CAMMÁ C., PETTA S., Di MARCO V., et al.: Insulin resistance is a risk factor for esophageal varices in hepatitis C virus cirrhosis. Hepatology, 49 (1): 195-203, 2009.

15- American Diabetes Association. 2. Classification and diagnosis of diabetes. Diabetes care, 39 (1): S13-22, 2016.

16- HSIEH P.S. and HSIEH Y.J.: Impact of liver diseases on the development of type 2 diabetes mellitus. World $\mathbf{J}$. Gastroenterol., 17 (48): 5240-5, 2011.

17- POREPA L., RAY J.G., SANCHEZ-ROMEU P., et al.: Newly diagnosed diabetes mellitus as a risk factor for serious liver disease. CMAJ, 182 (11): E526-31, 2010. 
18- KIM M.Y., BAIK S.K. and LEE S.S.: Hemodynamic alterations in cirrhosis and portal hypertension. Korean J. Hepatol., 16 (4): 347-52, 2010.

19- KONTUREK P.C., BRZOZOWSKI T., BURNAT G., et al.: Gastric ulcer healing and stress-lesion preventive properties of pioglitazone are attenuated in diabetic rats. J. Physiol. Pharmacol., 61 (3): 429-36, 2010.

20- THOMSEN R.W., RIIS A., CHRISTENSEN S., et al.: Diabetes and 30-day mortality from peptic ulcer bleeding and perforation: A Danish population-based cohort study. Diabetes Care, 29 (3): 805-10, 2006

21- QUINTANA J.O., GARCÍA-COMPEAN D., GONZÁLEZ J.A., et al.: The impact of diabetes mellitus in mortality of patients with compensated liver cirrhosis-a prospective study. Ann. Hepatol., 10 (1): 56-62, 2016.

22- ELBAIH A.H., ABDO M.M., KHALIL K.A., et al.: Correlation between diabetes mellitus and the clinical outcome of acute variceal bleeding in cirrhotic patients in Suez Canal University Hospital, Ismailia, Egypt. Med., 6 (2): 338-46, 2017.

23- RAMACHANDRAN T.M., RAJNEESH A.H.R., ZACHARIA G.S., et al.: Cirrhosis of Liver and Diabetes Mellitus: The Diabolic Duo? J. Clin. Diagn. Res., 11 (9): OC01OC05, 2017.

24- HARRISON S.A., BRUNT E.M., GOODMAN Z.D., et al.: Diabetic hepatosclerosis: Diabetic microangiopathy of the liver. Arch. Pathol. Lab. Med., 130 (1): 27-32, 2006.

25- GINES P. and SCHRIER R.W.: Renal failure in cirrhosis. N. Engl. J. Med., 361 (13): 1279-90, 2009.

26- CHEN Y.W., CHEN H.H., WANG T.E., et al.: The dissociation between the diabetes and both Child-Pugh score and in-hospital mortality in cirrhotic patients due to hepatitis B, hepatitis C, or alcoholic. Hepatol. Int., 5 (4): 955-64, 2011

27- ELKRIEF L., CHOUINARD P., BENDERSKY N., et al.: Diabetes mellitus is an independent prognostic factor for major liver-related outcomes in patients with cirrhosis and chronic hepatitis C. Hepatology (Baltimore, MD), 60 (3): 823-31, 2014.

28- LIU T.L., TROGDON J., WEINBERGER M., et al.: Diabetes is associated with clinical de-compensation events in patients with cirrhosis. Digestive diseases and sciences, 61 (11): 3335-45, 2016.

29- GUNDLING F., SEIDL H., STRASSEN I., et al.: Clinical manifestations and treatment options in patients with cirrhosis and diabetes mellitus. Digestion, 87 (2): 75-84, 2013

30- BUTT Z., JADOON N.A., SALARIA O.N., et al.: Diabetes mellitus and decompensated cirrhosis: Risk of hepatic encephalopathy in different age groups. J. Diabetes, 5 (4): 449-55, 2013.

31- ZEESHAN B., NAUMAN A., OSMAN N., et al.: Diabetes mellitus and decompensated cirrhosis: Risk of hepatic encephalopathy in different age groups. J. Diabetes, 5 (4): 449-55, 2013.

32- THAPA P.B., MAHARJAN D.K., TAMANG T.Y., et al.: Clinical correlation between Child Pugh's score and oesophageal varices in upper gastrointestinal endoscopy in cirrhotic patient. Journal of Kathmandu Medical College, 4 (4): 135-9, 2017.

33- DEEPAK B. and GOLABAVI N.: Prediction of Oesophageal Varices in Hepatic Cirrhosis by Noninvasive Markers. Clin. Gastroenterol. Hepatol., 15 (1): e17, 2017.

34- ASHRAF D.G. and EL-SAYED I.: Esophageal varices predictive score in liver cirrhosis. The Egyptian Journal of Internal Medicine, 30 (2): 72, 2018.

35- GARCÍA-COMPEÁN D., GONZÁLEZ-GONZÁLEZ J.A., LAVALLE-GONZÁLEZ F.J., et al.: Current concepts in diabetes mellitus and chronic liver disease: Clinical outcomes, hepatitis $\mathrm{C}$ virus association, and therapy. Dig. Dis. Sci., 61 (2): 371-80, 2016.

36- PERME O., SINGH Y.I., SINGH K.R., et al.: Prevalence of diabetes in chronic liver disease patient admitted in medicine ward in RIMS Hospital, Imphal. J. Med. Soc., 30 (2): 84, 2016.

37- JEON H.K., KIM M.Y., BAIK S.K., et al.: Hepatogenous diabetes in cirrhosis is related to portal pressure and variceal hemorrhage. Dig. Dis. Sci., 58 (11): 3335-41, 2013.

38- ARSHAD M.F., ZEESHAN B., KAMRAN M., et al.: Impact of diabetes mellitus on frequency and severity of hepatic encephalopathy in liver cirrhosis. Endocrine Abstracts, 1479-6848, 2016.

39- HUANG Y.W., YANG S.S., FU S.C., et al.: Increased risk of cirrhosis and its decompensation in chronic hepatitis $\mathrm{C}$ patients with new-onset diabetes: A nationwide cohort study. Hepatol., 60 (3): 807-14, 2014.

40- KWON S.Y.: Prevalence and clinical significance of diabetes mellitus in patients with liver cirrhosis. Taehan Kan Hakhoe chi=The Korean J. Hepatol., 9 (3): 205-11, 2003.

41- YANG C.H., CHIU Y.C., CHEN C.H., et al.: Diabetes mellitus is associated with gastroesophageal variceal bleeding in cirrhotic patients. The Kaohsiung J. Med. Sci., 30 (10): 515-20, 2014.

42- KHAFAGA S., KHALIL K., ABDOU M., et al.: Acute variceal bleeding in patients with liver cirrhosis with and without diabetes. Liver Res. Open J., 1 (1): 14-20.

43- SAEED M.J., OLSEN M.A., POWDERLY W.G., et al.: Diabetes mellitus is associated with higher risk of developing decompensated cirrhosis in chronic hepatitis $\mathrm{C}$ patients. J. Clin. Gastroenterol., 51 (1): 70-7, 2017.

44- ORSI E., GRANCINI V., MENINI S., et al.: Hepatogenous diabetes: Is it time to separate it from type 2 diabetes? Liver Int., 37 (7): 950-62, 2017.

45- RAMESH R.: Hepatogenous diabetes: An underestimated problem of liver cirrhosis. Indian J. Endocrinol. Metab., 22 (4): 552-9, 2018.

46- HUNAYSH A.Y.: Prediction of Early Rebleeding and Mortality after Acute Esophageal Variceal Hemorrhage among Yemeni Patients in Major Hospitals-Sana'a. Open J. Gastroenterol., 6 (8): 214-22, 2016.

47- GROZA I., ACALOVSCHI M., PASCA S., et al.: Factors predictive of relapse in variceal upper gastrointestinal bleeding. A prospective study in patients with liver cirrhosis. Human \& Veterinary Medicine, 9 (4): 1-12, 2017. 
48- SARWAR S., KHAN A.A. and TARIQUE S.: Comparison of MELD, Child Pugh score and Rockall score for predicting re bleeding and in-hospital mortality in patients of variceal bleeding. J. Coll Physicians Surg. Pak., 18 (8): 524-5, 2008.

49- EBRAHIMI M., REIHANI H., SHEIKHIAN M., et al.: Re-Bleeding in Patients With Cirrhosis: Evaluation of Esophageal and Gastric Variceal Bleeding and Their Relationship With a Model for the End-Stage Liver Disease (MELD) Score and Child-Pugh Score. Razavi Int. J. Med., 2 (2): 1-6, 2014.

50- GOLDIS A., LUPUSORU R., GOLDIS R., et al.: Prognostic Factors in Liver Cirrhosis Patients with Upper Gastrointestinal Bleeding. Biol. Med., 10 (1): 1-11, 2018.

51- ASSEM M., AL SAYED M., METWALLY K., et al.: Comorbidity of diabetes mellitus and bleeding esophageal varices. Internal Medicine/Medicina Int., 13 (1): 1-9, 2016.
52- MOREAU R., CHAGNEAU C., HELLER J., et al.: Hemodynamic, metabolic and hormonal responses to oral glibenclamide in patients with cirrhosis receiving glucose. Scand J. Gastroenterol., 36: 303-8, 2001.

53- TIJERA F.H.-D.L., SERVIN-CAAMAÑO A., NAVARROESTRADA A.E., et al.: Uncontrolled diabetes increases all causes of mortality and particularly cardiovascular death in patients with cirrhosis. J. Hepatol., 68: S718, 2018.

54- HSIANG J.C., GANE E.J., BAI W.W., et al.: Type 2 diabetes: A risk factor for liver mortality and complications in hepatitis B cirrhosis patients. J. Gastroenterol. Hepatol., 30 (3): 591-9, 2015.

55- FAIGEL D.O. and METZ D.C.: Prevalence, etiology, and prognostic significance of upper gastrointestinal hemorrhage in diabetic ketoacidosis. Dig. Dis. Sci., 41 (1): 18, 1996.

\section{تقييم مرض السكرى كعامل خطر مستقل لنزيف دوالى المعدة والمرئ فى مرضى التليف الكبلى}

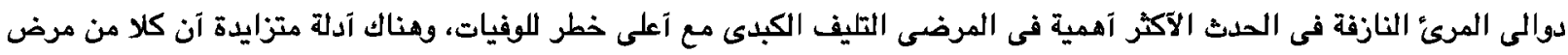

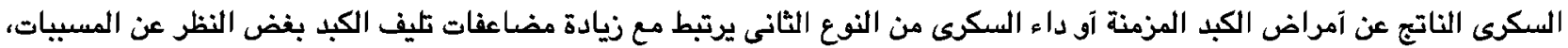
ومن ثم زيادة في معدل الوفيات عن أمرات التيك.

الهدف من البحث: توضيت إذا كان السكر بالدم هو عامل خطر مستقل لنزيف دوالى المريّ في مرضى التليف الكبدى. وقد تم تقسيم

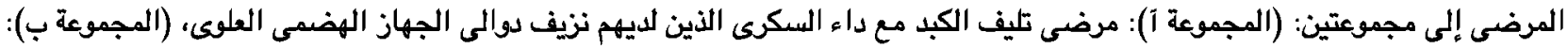

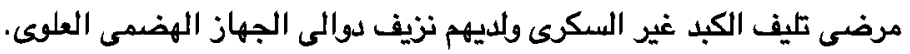

ولقد إتضح من النتائج آن وجود مرض السكرى إرتبط مع حدوث مضاعفات آكثر لتلف الكبد ـ كما وجدنا آن مرض السكرى كان له تآثير

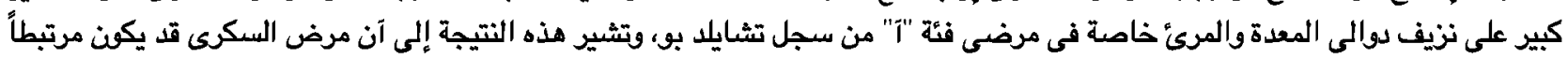

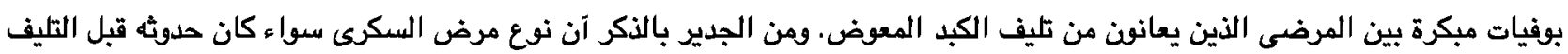

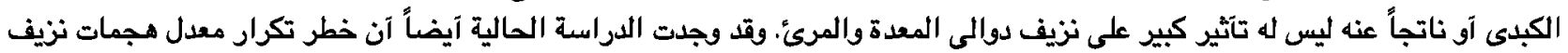

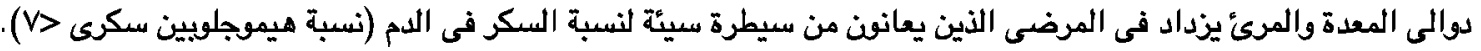
ولذلك توصى دراستتا بالآتى:

$$
\text { • • إجراء مسبح لداء السكرى لجميع مرضى التيف الكبدى، وذلك بسبب تآثيره السلبى على مرض الكبد. }
$$

• إدراج مرض السكرى مع التصنيفات المستخدمة فى التليف الكبدى مثل سجل تثايلد بو ومقياس تحديد المراحل النهائية لمرض الكبد (MELD)

• هناك حاجة لدراسات إضافية لتقيم مدى تآثير السيطرة على مرض السكرى فى تطود مضاعفات التليف الكبلى. 